\title{
Study on Properties of Silicon Oxycarbide Thin Films Prepared by RF Magnetron Sputtering
}

\author{
Tao Chen ${ }^{\text {, }}$ Maojin Dong, Jizhou Wang, Ling Zhang and Chen Li
}

\author{
Science and Technology on Surface Engineering Laboratory, Lanzhou Institute of Physics, \\ Lanzhou 730000, China \\ ${ }^{a}$ chensuix@126.com
} Keywords: Silicon oxycarbide, thin films, RF magnetron sputtering, optical performance,
indentation hardness.

\begin{abstract}
Silicon oxycarbide(SiCO)thin films are a kind of glassy compound materials, which possess many potential excellent properties such as thermal stability, big energy band, big refractive index and high hardness, and have many potential applications in space. The preparation processes of SiCO thin films synthesized by RF magnetron sputtering with different substrate temperature, working pressure or sputtering power were studied. And varied surface analysis methods were used to characterize the optical and mechanical properties of SiCO thin films. The dependence of the properties to the process parameters was else studied. The results of the properties SiCO thin films deposited on K9 glass indicated that lower substrate temperature and sputtering power, higher working pressure could get SiCO thin films with better transmittance. The indentation hardness HIT of SiCO thin films on $\mathrm{K} 9$ glass had dependence on substrate temperature and sputtering power, and the rise of substrate temperature could enhance the indentation hardness HIT evidently. The indentation hardness of sample K2 and M2 which synthesized when substrate temperature was $473 \mathrm{~K}$ was as high as $18.15,13.20 \mathrm{GPa}$ respectively.
\end{abstract}

\section{Introduction}

$\mathrm{SiC}$ is the third wide semiconductor material, pure $\mathrm{SiC}$ crystal has tetrahedron structure like diamond, which possess many potential excellent properties such as low density $\left(\sim 3.2 \mathrm{~g} \cdot \mathrm{cm}^{-3}\right)$, high thermal conductivity $\left(\sim 4.0 \mathrm{~W} \cdot{ }^{\circ} \mathrm{C}^{-1} \cdot \mathrm{cm}^{-1}\right)$, low coefficient of thermal expansion $(\sim$ $3.8 \times 10^{-6} \mathrm{C}^{-1}$ ) and high hardness (9.2 9.3 Mohs hardness) [1,2]. Due to wide bandgap (2.36 $3.26 \mathrm{eV}$ ) , SiC material has short wavelength luminescence [3].So it can be used short wavelength luminescence device and UV detector. On the side, SiC material can be used in aviation and Aerospace because of high disruptive field and strong resist radiation.

$\mathrm{SiC}$ film is a excellent optical film material, it can be used as AR films of photoelectronic device, solar cell and window protective material $[4,5]$. But it has absorb in the short wavelength, which reduce its applications. $\mathrm{SiO}_{\mathrm{x}}$ film has high transmittance, so it can be used protective films of optical device [6-8]. Silicon oxycarbide (SiCO) thin films are a kind of glassy compound materials, which possess many potential excellent properties such as thermal stability, big energy band, high hardness, and have many potential applications in space.

The preparation processes of SiCO thin films synthesized by RF magnetron sputtering with different substrate temperature, working pressure or sputtering power were studied in the paper,. And varied surface analysis methods were used to characterize the optical and mechanical properties of SiCO thin films. The dependence of the properties to the process parameters was else studied.

\section{Experimental}

\section{Sample preparation.}




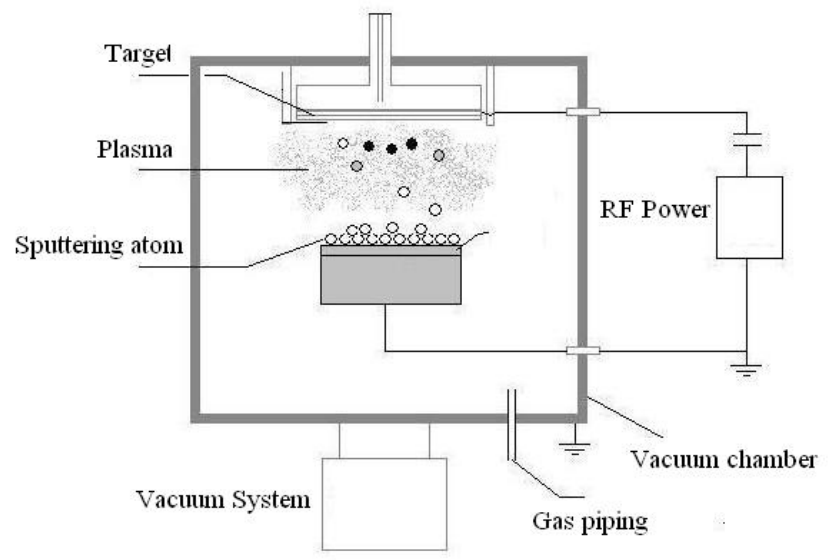

Fig.1 Sketch of RF magnetron sputtering system

SiCO thin films were prepared by RF magnetron sputtering in Fig.1. The substrate is K9 glass. The work gas is Ar, the sputtering target is SiCO ceramics. The background pressure is $3 \times 10-3 \mathrm{~Pa}$. Working pressure is $1 \sim 2 \mathrm{~Pa}$. The substrate temperature is $373 \sim 523 \mathrm{~K}$. The sputtering power is 150 400W.

\section{Sample characterization.}

The morphologies of SiCO thin films were observed by SEM (JSM-6701F, Japan). The component of SiCO thin films were tested by XPS (PHI-5702, America). The spectrum of SiCO thin films were tested by UV/VIS/IR spectrophotometer (Lambda 900, America). The refractive index of SiCO thin films were tested by ellipse polarization light device (L116E, America). The indentation hardness of SiCO thin films were tested by hardness testing device (Switzerland).

\section{Results and discussion}

\section{SEM analysis.}

The morphologies of SiCO thin films were observed by SEM. Fig.2 shows the SEM micrograph of SiCO thin films. It should be noticed that the surface of SiCO thin films were flat and compact, well distributed particle size of $100 \mathrm{~nm}$ approximately.

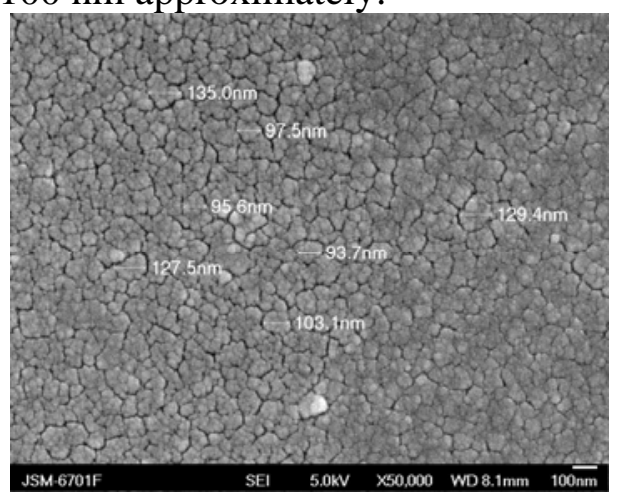

Fig.2 The SEM micrograph of SiCO films（T=423K,P=2Pa,W=300W $)$

\section{XPS analysis.}

The component of SiCO thin films were tested by XPS. Fig.3 shows the XPS of SiCO thin films. It should be noticed that SiCO thin films is composed of Si, C and O element. The ratio is 1: 1: 0.8. Si element exists in the form of $\mathrm{Si}-\mathrm{C}, \mathrm{SiO}_{\mathrm{x}}$ and $\mathrm{O}-\mathrm{Si}-\mathrm{C}, \mathrm{C}$ element exists in the form of Si-C, $\mathrm{Si}-\mathrm{C}-\mathrm{O}$ and $\mathrm{C}-\mathrm{O}$, and $\mathrm{O}$ element exists in the form of $\mathrm{SiO}_{\mathrm{x}}, \mathrm{O}-\mathrm{C}$. 


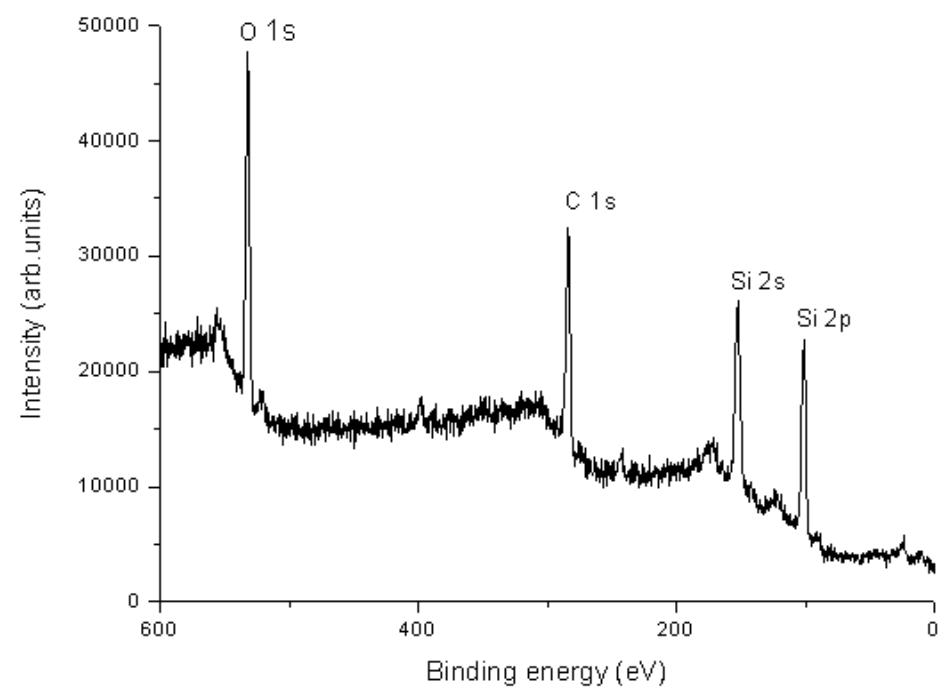

Fig.3 The XPS spectra of SiCO thin films（T=423K,P=2Pa,W=300W）

\section{Optical performance.}

The spectrum of SiCO thin films were tested by UV/VIS/IR spectrophotometer. Fig.4 shows the spectrum of SiCO thin films with different deposition temperature. Sample A2, B2, C2 and D2 were prepared at working pressure of $1 \mathrm{~Pa}$ and sputtering power of $300 \mathrm{~W}$. The deposition temperature is $373 \mathrm{~K}, 423 \mathrm{~K}, 473 \mathrm{~K}$ and $523 \mathrm{~K}$ respectively. The results show that influence of deposition temperature on the spectrum of SiCO thin films was unapparent.

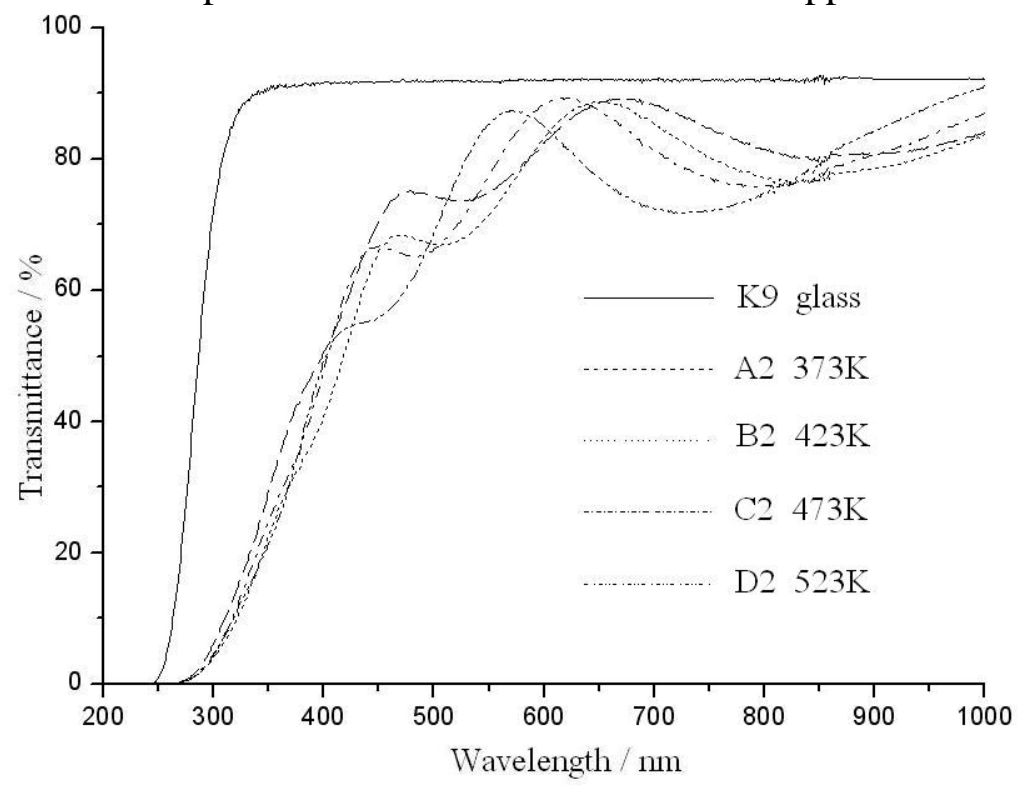

Fig.4 The spectrum of SiCO thin films with different deposition temperature

Fig.5 shows the spectrum of SiCO thin films with different working pressure. Sample B2 and E2 were prepared at temperature of $423 \mathrm{~K}$ and sputtering power of $300 \mathrm{~W}$, and the working pressure is $1 \mathrm{~Pa}$ and $2 \mathrm{~Pa}$, respectively. The results show that influence of working pressure on the spectrum of SiCO thin films was obvious. With high working pressure, the spectrum of SiCO thin films present blue shift. 


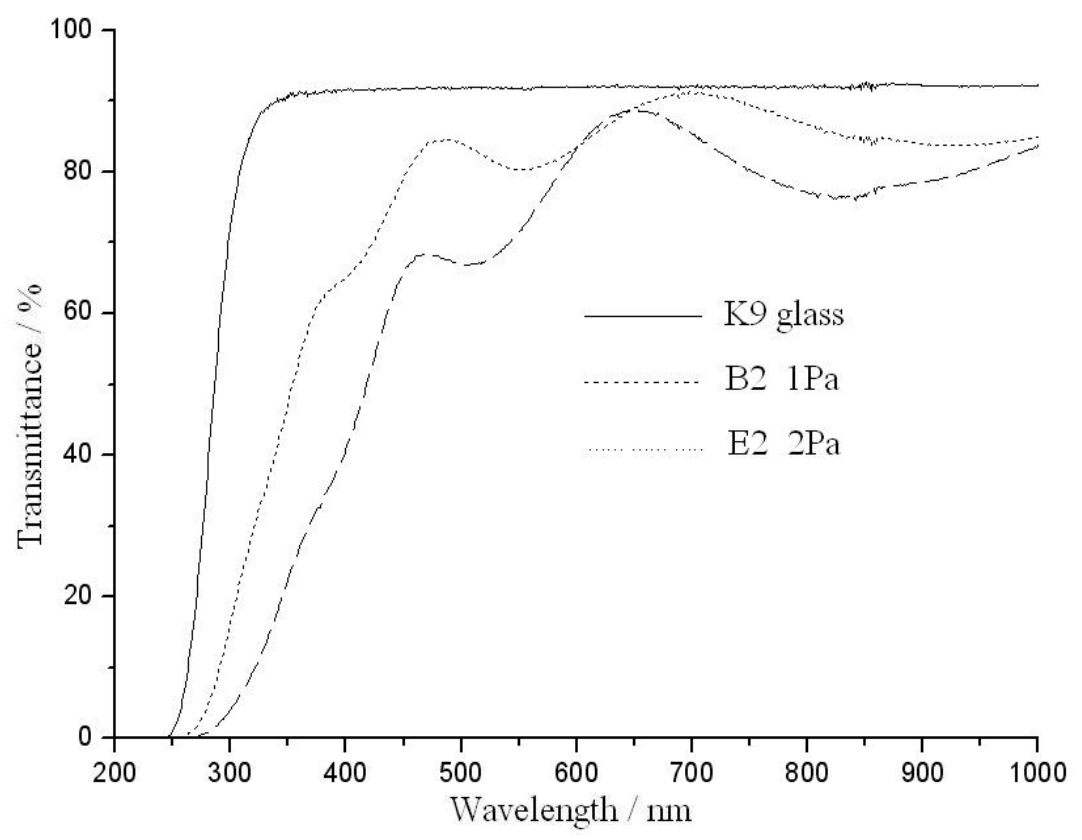

Fig.5 The spectrum of SiCO thin films with different working pressure

Fig.6 shows the spectrum of SiCO thin films with different sputtering power. Sample B2, F2 and G2 were prepared at working pressure of $1 \mathrm{~Pa}$ and substrate temperature of $423 \mathrm{~K}$. The sputtering power is $300 \mathrm{~W}, 200 \mathrm{~W}$ and $400 \mathrm{~W}$, respectively. The results show that influence of sputtering power on the spectrum of SiCO thin films was obvious. With high sputtering power, the spectrum of SiCO thin films present red shift.

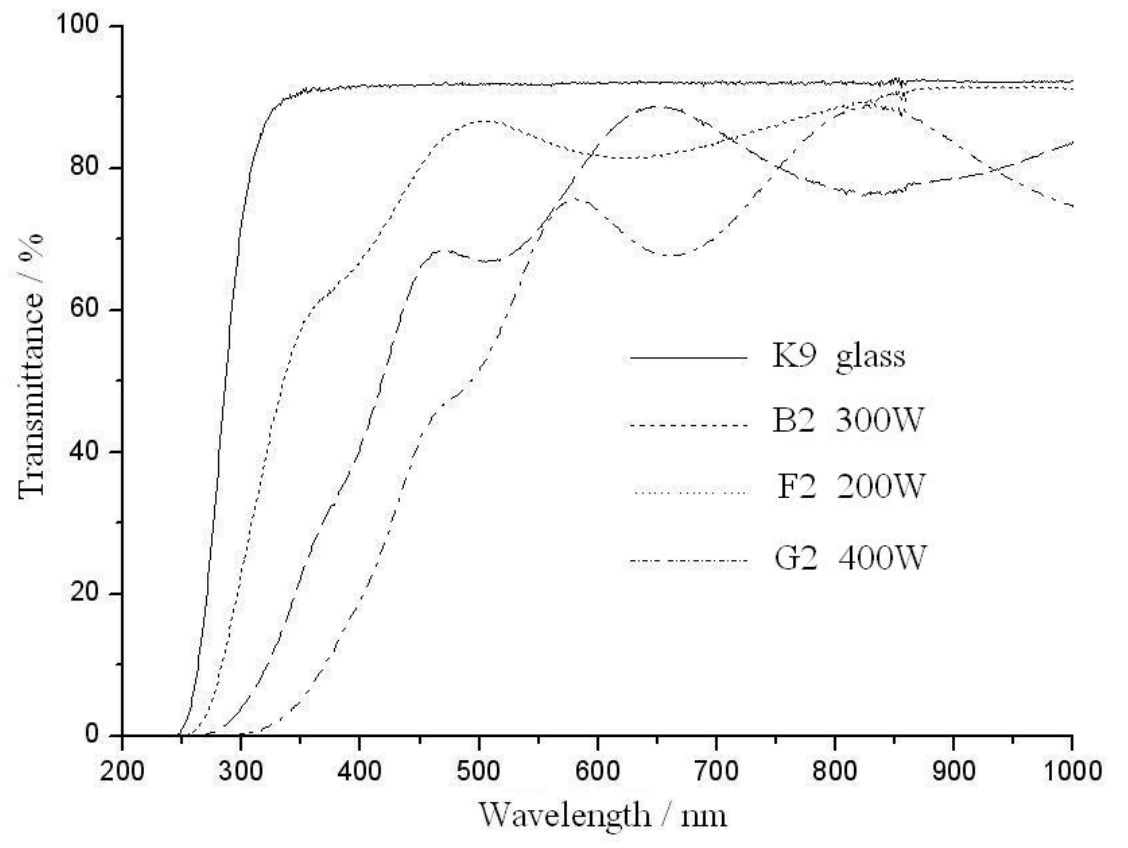

Fig.6 The spectrum of SiCO thin films with different sputtering power

\section{Indentation hardness.}

The indentation hardness of SiCO thin films were tested by hardness testing device. Table 1 is the results of indentation hardness of SiCO thin films. The results show that the indentation hardness of SiCO thin films had dependence on substrate temperature and sputtering power. The rise of substrate temperature could enhance the indentation hardness evidently. The indentation hardness of sample K2 and M2 which synthesized when substrate temperature was $473 \mathrm{~K}$ was as high as $18.15 \mathrm{GPa}, 13.20 \mathrm{GPa}$ respectively. 
Table 1 the results of indentation hardness of SiCO thin films

\begin{tabular}{ccccc}
\hline sample & $\begin{array}{c}\text { working pressure } \\
{[\mathbf{P a}]}\end{array}$ & $\begin{array}{c}\text { deposition temperature } \\
{\left[{ }^{\circ} \mathrm{C} \text { ] }\right.}\end{array}$ & $\begin{array}{c}\text { sputtering power } \\
\text { [W] }\end{array}$ & $\begin{array}{c}\text { indentation hardness } \\
\text { [GPa] }\end{array}$ \\
\hline H2 & 1 & 150 & 300 & 8.701 \\
I2 & 1 & 150 & 300 & 7.401 \\
K2 & 1 & 200 & 300 & 18.150 \\
M2 & 1 & 200 & 200 & 13.200 \\
\hline
\end{tabular}

\section{Conclusions}

Influence of working pressure and sputtering power on the spectrum of SiCO thin films was large. When high working pressure or low sputtering power got, the spectrum of SiCO thin films changed to short wavelength. The indentation hardness of SiCO thin films had dependence on substrate temperature and sputtering power. The rise of substrate temperature could enhance the indentation hardness evidently.

\section{References}

[1] Cary L Harris et al. Properties of Silicon Carbide [M]. INSPEC, Institution of Electrical Engineers, London, 1995.

[2] Stephen E. Saddow, Anant Agarwal et al. Advances in Silicon Carbide Processing and Applications [M]. Artech House, Inc. New York, 2001.

[3] N.I. Klyui, V.G. Litovchenko, A.G. Rozhin et al. Silicon solar cells with antireflection diamond-like carbon and silicon carbide films [J]. Solar Energy Materials \& Solar Cells, 2002, 72: $597 \sim 603$.

[4] Shinsuke Miyajima, Akira Yamada, Makoto Konagai. Highly conductive microcrystalline silicon carbide films deposited by the hot wire cell method and its application to amorphous silicon solar cells [J]. Thin Solid Films, 2003, 430: 274 277.

[5] Y. Huang, T. Chen, A. Gordijn et al. Preparation of microcrystalline silicon solar cells on microcrystalline silicon carbide window layers grown with HWCVD at low temperature [J]. Journal of Non-Crystalline Solids, 2008, 354: 2430 2434.

[6] H. Omanda, T. Brousse, C. Marhic, et al. Improvement of the Thermal Stability of $\mathrm{LiNi}_{0.8} \mathrm{Co}_{0.2} \mathrm{O}_{2}$ Cathode by a SiOx Protective Coating [J]. J. Electrochem. Soc., 2004, 151(6): A922 A929.

[7] Cheng $\mathrm{Xu}$, Hongcheng Dong, Jianyong $\mathrm{Ma}$, et al. Influences of $\mathrm{SiO}_{2}$ protective layers and annealing on the laser-induced damage threshold of $\mathrm{Ta}_{2} \mathrm{O}_{5}$ films [J]. Chinese Optics of Letters, 2008, 6(3): 228 230.

[8] Ulrike Schulz, Stefan Jakobs, and Norbert Kaiser. $\mathrm{SiO}_{2}$ protective coatings on plastic optics deposited with plasma IAD [J]. Proc. SPIE 2776, 1996: 169 174. 